\title{
Non-Hodgkin lymphoma
}

INSERM

\section{Source}

INSERM. (1999). Orphanet: an online rare disease and orphan drug data base. NonHodgkin lymphoma. ORPHA:547

Non-Hodgkin malignant lymphomas(NHL) is a heterogeneous group of malignant tumors of the lymphoid system. 